\title{
Mauriac Syndrome: A Rare Complication of Poorly Controlled Diabetes Mellitus
}

\author{
Ashish Tiwaria, Shrivastava Jyotsna ${ }^{\mathrm{a}}$, Agrawal Amit ${ }^{\mathrm{a}, \mathrm{b}}$
}

\begin{abstract}
Mauriac syndrome is one of the complications of poorly controlled diabetes mellitus type 1 . Common presenting features include short stature, growth retardation, moon facies, protuberant abdomen, and proximal muscle wasting. We hereby report a case of 15 year old female who presented with clinical featues of Mauriac syndrome.
\end{abstract}

Keywords: Mauriac syndrome; Diabetes mellitus; Complication

\section{Introduction}

Poorly controlled diabetes is a frequent problem in developing countries leading to many complications related to underinsulinisation and Mauriac syndrome is one of them. Mauriac syndrome is a complication in diabetes mellitus type 1, which includes short stature, glycogen laden enlarged liver, limited joint mobility, tight waxy skin, growth maturation delay, moon facies, protuberant abdomen, and proximal muscle wasting and also it is frequently associated with retinopathy and nephropathy $[1,2]$. We hereby report a case of mauriac syndrome as very few cases have been reported previously in India [3].

\section{Case Report}

A 15-year-old female, referred to us for evaluation of short stature and delayed puberty. Patient also had decreased vi-

Manuscript accepted for publication July 11, 2013

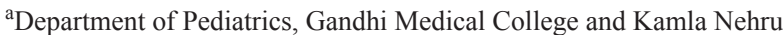
Hospital, Bhopal, MP, India

${ }^{\mathrm{b}}$ Corresponding author: Agrawal Amit, 28, Ravidas Nagar, Near Nizamuddin Colony, Indrapuri, Bhopal, MP - 462023, India.

Email: agrawaldramit@yahoo.co.in
}

doi: http://dx.doi.org/10.4021/ijcp103w sion and tingling sensation in the upper and lower limbs since one month. She was diagnosed to have type 1 diabetes mellitus (DM) 10 year back, and was on subcutaneous premixed insulin. However, compliance as well as sugar monitoring was very poor. Therefore, she had been repeatedly hospitalized with frequent manipulations in the insulin dosing and shedule. On examination, patient was short statured $(102 \mathrm{~cm}$, less then $3 \mathrm{rd}$ percentile), her weight for age was less then 3 rd percentile, BMI was 14 (between 5 - 10th percentile), had protruded abdomen with hepatospleenomegaly, muscle wasting and delayed puberty (SMR stage 1). She was hypertensive, had ketonuria (++) and glycosuria. Investigations showed normal hemogram, normal liver and renal function test. Ultrasound abdomen revealed hepatospeenomegaly with altered liver echotexture and fatty infiltration of the liver. Her premeal blood sugar was $420 \mathrm{mg} \%$, $\mathrm{HBA}_{1} \mathrm{C}$ was $13.1 \%$ (normal $<6 \%$ ), microalbuminuria $>160 \mu \mathrm{g} / \mathrm{mL}$ (normal $<18 \mu \mathrm{g} / \mathrm{mL}$ ) with higher albumin/creatinine ratio. Patient also found to have motor axonal neuropathy on nerve conduction velocity, microaneurysm on fundus examination and osteopenia on skeletogram. Blood gas analysis suggested no acid base imbalance, and no electrolyte abnormality. Thyroid function tests were within normal range. Based on history, examination and investigation findings, final diagnosis of Mauriac syndrome was made. Patient was shifted to strict dietary management and high dose premixed insulin, high dose calcium, vitamin D3 and multivitamin. After 2 months of therapy, patient improved symptomatically, premeal sugar came down to $100-150 \mathrm{mg} \%$ and there was reduction in hepatomegaly.

\section{Discussion}

Mauriac syndrome was first described by Mauriac in 1930 in children with type $1 \mathrm{DM}$ presenting with clinical features of growth failure, maturation delay, hepatomegaly and abdominal distension [4]. Most of the cases occur in adolescence with equal sex ratio. On the basis of the presence or absence of obesity, 2 different forms of Mauriac syndrome have been described. Pathogenesis of the growth retardation is not clear but thought to be multifactorial. Inadequate glucose to the 
tissues, decreased insulin like growth factor 1 and growth hormone level, and hypercortisolism may contribute to delayed growth and puberty. Hepatomegaly is thought to be due to glycogen deposition in the liver [5, 6]. Growth failure, delayed puberty and hepatomegaly in Mauriac syndrome improve with glycemic control [3]. This is a case of adolescent female with poorly controlled DM who found to have short stature. With the additional findings of gross hepatomegaly, delayed puberty and a Cushingoid habitus, she was diagnosed with Mauriac syndrome. In this case, poor compliance because of poor literacy was the main cause behind the poorly controlled diabetes.

\section{Disclaimer}

None.

\section{Competing Interest}

None.

\section{References}

1. Mahesh S, Karp RJ, Castells S, Quintos JB. Mauriac syndrome in a 3-year-old boy. Endocr Pract. 2007;13(1):6366.

2. Kim MS, Quintos JB. Mauriac syndrome: growth failure and type 1 diabetes mellitus. Pediatr Endocrinol Rev. 2008;5(Suppl 4):989-993.

3. Patidar PP, Philip R, Saran S, Gupta KK. A rare case of Mauriac syndrome. Indian $\mathrm{J}$ Endocrinol Metab. 2012;16(3):486-487.

4. Mauriac P. Gros ventre, hepatomegalie, troubles de croissance chez les enfants diabetiques traits depuis plusiers annee par l'insuline. Gaz Hebd Med Bordeaux 1930;26:402-410.

5. Lee RG, Bode HH. Stunted growth and hepatomegaly in diabetes mellitus. J Pediatr. 1977;91(1):82-84.

6. Klein R, Marks JF, Roldan E, Sherman FE, Fetterman GH. The occurrence of peripheral edema and subcutaneous glycogen deposition following the initial treatment of diabetes mellitus in children. J Pediatr. 1962;60:807814 . 